This item was submitted to Loughborough's Research Repository by the author.

Items in Figshare are protected by copyright, with all rights reserved, unless otherwise indicated.

\title{
Exploring design for happiness in the home and implications for future domestic living
}

PLEASE CITE THE PUBLISHED VERSION

http://www.drs2016.org/\#drs2016

\section{PUBLISHER}

(c) The Authors. Published by the Design Research Society

\section{VERSION}

AM (Accepted Manuscript)

\section{PUBLISHER STATEMENT}

This work is made available according to the conditions of the Creative Commons Attribution-NonCommercial 4.0 International (CC BY-NC 4.0) licence. Full details of this licence are available at: http://creativecommons.org/licenses/by-nc/4.0/

\section{LICENCE}

CC BY-NC 4.0

\section{REPOSITORY RECORD}

Doyle, Emily Corrigan, M. Carolina Escobar-Tello, and Kathy Pui Ying Lo. 2019. "Exploring Design for Happiness in the Home and Implications for Future Domestic Living”. figshare.

https://hdl.handle.net/2134/20781. 


\title{
Future-Focused Thinking
}

\section{Exploring Design for Happiness in the Home and Implications for Future Domestic Living}

\author{
Emily Corrigan-Doyle ${ }^{1}$, Carolina Escobar-Tello², Kathy Pui Ying Lo ${ }^{3}$ \\ ${ }^{1}$ Loughborough Design School and School of the Arts, Loughborough University, Loughborough, UK \\ ${ }^{2}$ Loughborough Design School, Loughborough University, Loughborough, UK \\ ${ }^{3}$ Loughborough School of the Arts, Loughborough University, Loughborough, UK \\ E.Corrigan-Doyle@lboro.ac.uk
}

\begin{abstract}
Home can influence our happiness through the activities it affords. Furthermore, previous research has indicated commonalities between happy, and sustainable societies but many of current home practices are unsustainable. This research aims to explore design for happiness as a means to future sustainable, and happier domestic lifestyles. This paper discusses the first study in which photo elicitation method was used with home-owning families to locate home happiness triggers. This method elicited photography of two representative days of the participants' home life. Participants were then questioned in follow-up semistructured interviews. From this, happiness home needs were conceptualised and connections were drawn to happy sustainable societies. This paper discusses these results and identifies that strong family bonds, facilitated by time relaxing, socialising and pursuing interests together, are core contributors to happier, and sustainable homes. The implications for design for happiness in the home are also discussed and proposed for future work.
\end{abstract}

Keywords: design for happiness, future homes, photo elicitation, future design

\section{Introduction}

Our current way of life is unsustainable. Current GDP-based economies affect the environment, economy and society; they are reliant on high levels of material consumption, productivity, create excessive waste, and motivate neurosis. These lifestyles are not making us happier (Hofstetter, et al 2006; Diener and Seligman 2004) and have been linked to higher levels of stress, anxiety and depression (Kasser, et al 2014; ibid). Approximately 450 million people worldwide have mental health issues and 1 in 6 people are affected in the UK every year (WHO 2001). Designers, "perceived as mere stylists to a (rampant) consumer society" 
are responsible for many of the mechanisms (i.e. excessive material consumption) that have led us to these current issues (Fuad-luke 2004). Design could, by the same course, influence a happier and more sustainable future (Manzini, et al 2006).

This process could begin in the home as it can be seen to reflect and strengthen current society and lifestyles. For example, the UK's current housing stock is one of the least efficient in Europe and accounts for approximately a quarter of all annual carbon emissions (UK Green Building Council 2015). Research in this field is already providing solutions that result in fewer impacts to the environment i.e. retrofitting current homes with energy saving technology (Horton 2005) and using more sustainably robust materials for future developments (Lazarus 2009). However, improvements to the social dimensions of this space might offer another viable avenue. Could design for happiness in the home provide an alternative means to future happy and sustainable living experiences?

The following paper begins with a brief description of happiness, related social practices and their effects on home. Design's role in happy and sustainable behaviours is then explained, followed by the influence of relational messages in service design and domestic social interactions. Subsequently, the home's role in positive affect is posed, and later expanded using findings from a photo elicitation study. To conclude, areas for design for happiness in the home are suggested.

\subsection{Concept of Happiness}

Happiness can be viewed as the central goal of life (Aristotle n.d./ 2004). It is a notoriously difficult concept to conceive of or measure as the meaning differs for every individual both culturally and personally. Seligman's (2002) definition of 'authentic happiness', offers a rich and applicable description for the purposes of this research. He discusses three dimensions or criteria of happiness that tend to occur sequentially: the experience of raw subjective feeling - the pleasant life; engagement (embodiment of strength and virtues) - the good life; and satisfaction (meaning and purpose) - the meaningful life (Diener \& Seligman 2004; Seligman and Royzman, 2003). In order to live a full and meaningful life, all three must be stimulated.

\subsection{Current Basis of Wellbeing is Unsustainable}

Our current happiness and wellbeing is largely based on products. Originating during the Industrial Revolution, complex devices capable of carrying out previous human labour tasks became increasingly accessible and were expected to extend free time and leisure for all (Manzini, et al 2006). Consequentially, we continue to seek fulfilment through material consumption of things and this occurs excessively as they tend to only satisfy happiness in a raw subjective manner through instant gratification (Hamilton 2003). Contemporary designs tend to be associated with 'disabling solutions' where skills and knowledge are grouped into devices, reducing or removing user involvement (Manzini, et al 2006). They, in this manner, 
fail to facilitate meaning or purpose in life and create a vicious cycle of consumption and "unfulfilled desire" (Boundy 2004 cited in Hamilton 2010; Diener and Seligman 2004).

\subsection{Roles of Home}

Today's homes and their contents mostly create contexts for convenience, speed and efficiency. However, lifestyles of high consumption and productivity do not necessarily correlate with long-term happiness (Hofstetter, et al 2006). Much of modern design tends to offer few opportunities for creative output or experience (Sander and Stappers, 2012) and many contemporary homes reflect this.

The home, playing significant role in our everyday lives, can be influential in our happiness. It provides shelter and a place to rest. It can be used to express identity through personalisation, portraying our hopes and ideals (Cristoforetti, et al 2011; De Botton 2006). Evidently, design can be used to influence interactions and experiences in spaces (Hassenzahl, et al 2013; Stickdorn and Schneider, 2011), it could thus be used to influence happier lifestyles in the home.

\section{Designing for Happiness (in the home)}

Design that contributes to happiness could create a healthier social context for sustainable behaviour to become the norm (Escobar-Tello and Bhamra, 2009). This is because designed objects, services and/or systems can be used to influence the type of interactions (sustainable or unsustainable) that take place in social environments, including in the home. This is particular to Service Design, where using tangible and intangible elements, it focuses on the holistic user experience and relies on positive exchanges for its value and success (Sangiorgi 2011; Stickdorn and Schneider, 2011). It could, hence, be used to promote sustainable interactions by encouraging happiness-enhancing activities in the domestic space. Home, created by on-going practices (Massey 2005; Ingold 2011; Dovey 1985), requires this systemic approach to facilitate and optimise positive experiences, and happiness.

Furthermore, the characteristics of sustainable societies appear to closely align with those that are happy (Escobar-Tello and Bhamra, 2009; Escobar-Tello 2010) (see figure 1). 


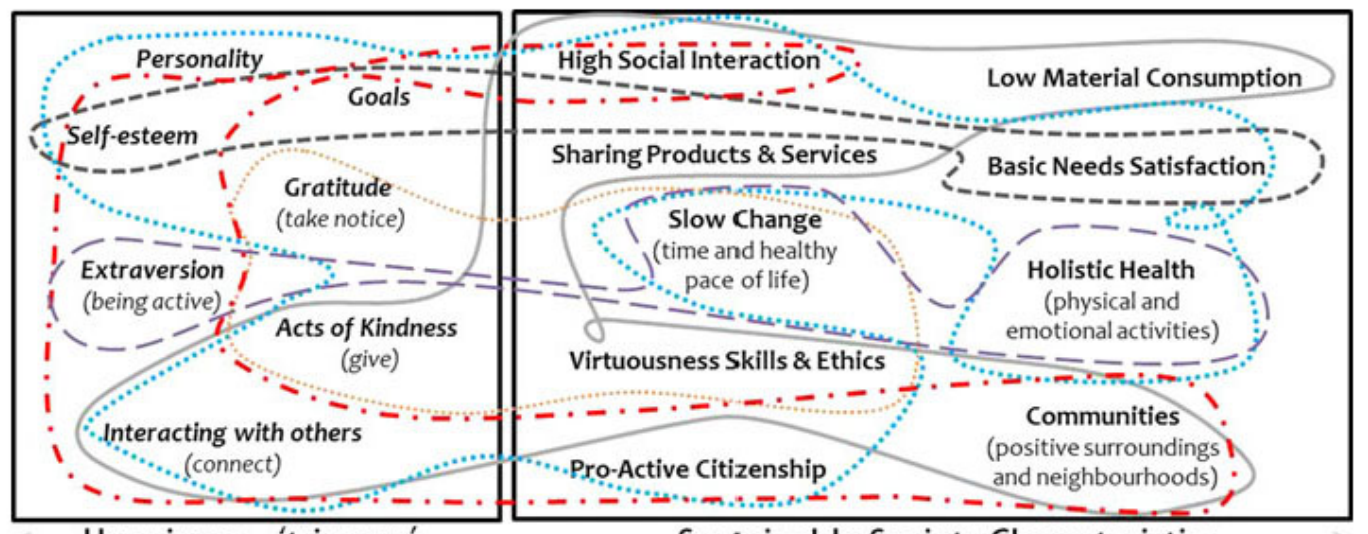

Happiness 'triggers'

Sustainable Society Characteristics
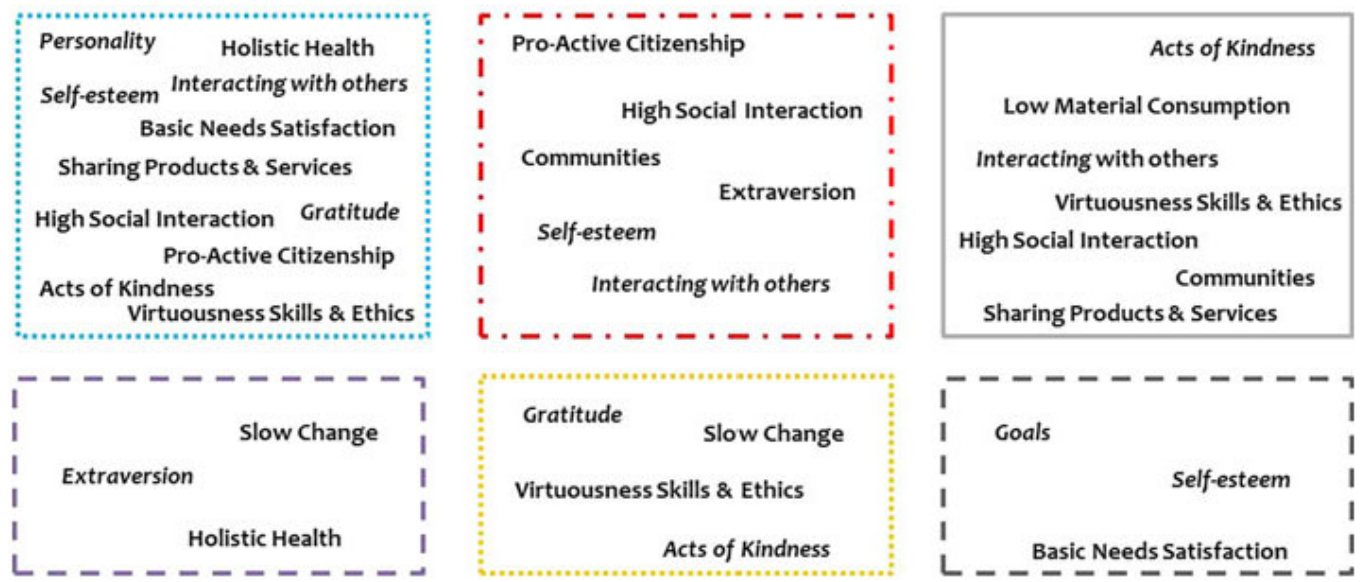

Figure 1 Examples of happiness triggers and sustainable society characteristics and their overlapping relationships (Escobar-Tello, 2013). Please refer to descriptions contained within the same coloured box and then observe how they are connected to other sustainable society characteristics or happiness triggers by viewing them in the black outlined boxes above.

Positive psychology (i.e. a relatively new field of psychology, which explores mental wellness as opposed to illness) has located various happiness triggers, which can lead to a "full life" (Segliman 2002; Pursuit of Happiness 2015). These include setting personal goals, expressing gratitude for the good things in one's life, exercising, connecting with others and undertaking acts of kindness (ibid; Escobar-Tello 2010). Characteristics of sustainable societies such as slow change, strong communities, basic needs satisfied and low material consumption can be seen to support happiness triggers and vice versa (Escobar-Tello 2010). For example, we build strong communities by sharing products and resources, interacting and undertaking acts of kindness. Happy individuals enjoy high levels of self-esteem and, once their basic needs are satisfied, they tend to consume less and are slow to change their belongings. However, this is a generalisation of what happy sustainable society characteristics could look like in many contexts. What are the corresponding practices for happy sustainable societies in the home and how could these be facilitated using design? 


\section{Relational Aspects of Design}

Encouraging positive domestic social interactions could be a viable approach for design for happiness in this context. For example, designed objects and environments of a service provider can exchange both planned and unplanned messages to users (Lo, 2011b, p.5), and similar interactions occur in the home. These can be influential in determining whether the service or home will be experienced as positive or negative.

\subsection{Relational Messages in Design}

The negative and positive emotions that people experience in everyday life can be strongly influenced by their interpretation of situations that confront them daily. According to appraisal theory (Roseman and Smith 2001) we have positive experiences - those judged as non-threatening, pleasant and/or a means to one's goals - in which we experience corresponding pleasant emotions and respond positively (ibid). The reverse is true when we appraise a situation negatively. Arnold's model (see figure 2) offers a linear simplification of how positive or negative emotions result from appraisals of an experience, sufficient for the purposes of this paper. A situation presents itself (situation box); the individual judges it to be of benefit or harm (appraisal box); this appraisal creates a corresponding positive or negative emotion (emotion box) that determines their subsequent action (action box).

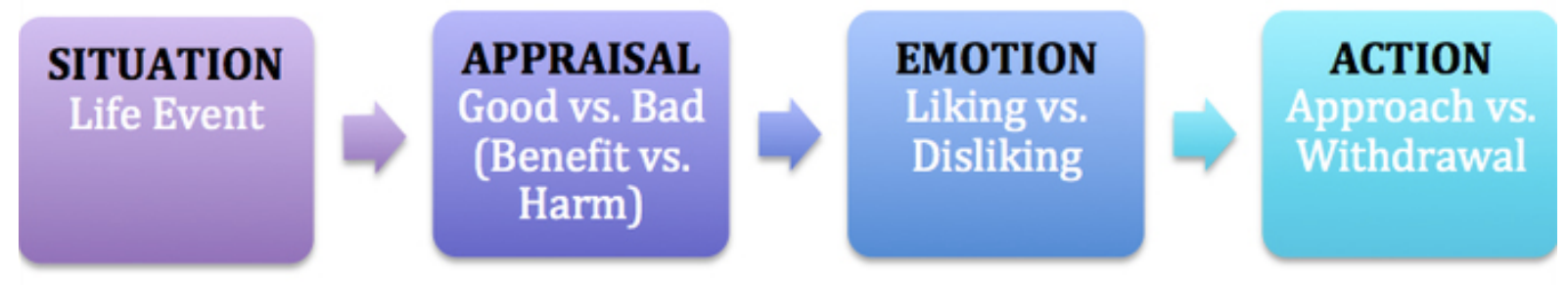

Figure 2 A model of Arnold's Theory of Appraisal Theory (from Reeve 2009).

These appraised emotional responses affect the interpretation of relational messages, which can be influential in the interactions taking place in design. For example, in service design, the design of a service or product-service system will have psychological impacts on the user upon contact through positive or negative appraisals (Lo 2011a), determining its future success (Cipolla and Manzini, 2009, p.46). This is controlled by the service evidence and the servicescape (i.e. the designed objects and/or surroundings of a service) that act as mediator between the consumer and provider (Lo, 2011b, p.5). Users can interpret both intended and unintended messages of the service providers' perceptions about them through this exchange (ibid). Relational messages play an important role in the creation of positive experiences and emotion from the interaction of design products, services or systems. 


\subsection{Relational Aspects of Home}

Similar interactions occur in the home. For instance, leaving dinner out for someone could be interpreted as a positive relational message by the viewer i.e. this person cares about me. However, if in the same instance a household member had left visual evidence that $s /$ he had eaten the other's food, this might create a negative relational message i.e. this person does not care about me. As these messages accumulate over time, they could influence future positive or negative interactions between occupants, deciphering whether a home will be experienced as happy and sustainable or the reverse. Furthermore, it could be theorised that certain happiness activities such as expressing gratitude, frequent social interaction and undertaking acts of kindness could encourage positive relational messages over negative. Accordingly, product service-systems could provide additional platforms for the promotion of domestic positive relational messages by facilitating these behaviours. With this consideration, design for happiness could foster and extend pleasant experiences.

\section{Home as a Facilitator (or Inhibitor) of Happiness}

The home is dynamic, comprising of the many evolving dialectic practices of individuals, objects and society (Massey 2005; Ingold 2011; Dovey 1985). It is through these engagements that identity (Cristoforetti, et al 2011) and habits are made in the home. Domestic occurrences, in turn, strengthen these personal and social routines. Their alternation could thus lead to happy or unhappy experiences. Furthermore, $40 \%$ of the variance of happiness is said to be under our personal control through our daily interactions (Lyubomirsky, et al 2005 cited in Hofstetter, et al 2006), therefore it is essential that home becomes a facilitator of happiness activities.

\subsection{Home as a Complex System}

The home, conceptualised by intricate interactions between occupants, artefacts and society (Massey 2005; Ingold 2011; Dovey 1985), is a complex system. However, recent initiatives to improve sustainability in this space have come from technological or built environment points of view where happiness aspects are neglected or collateral to the main results. For example, LEEDR (Low Effort Energy Demand Reduction) was a research project that looked at how people moved and interacted with technology in their homes (LEEDR 2014). Results from this included emotional rationales for these home practices i.e. to make home feel right (Pink 2013). However, technological use is just one way individuals facilitate sustainability in the home. Under a happiness perspective it is necessary to consider other aspects (i.e. happiness triggers) such as the nurturing of social relationships and acts of kindness, and how they are supported or inhibited in this context.

Furthermore, previous built environment sustainable interventions have been met with heavy resistance. For example, Affinity Sutton (a social housing organisation) received a $50 \%$ refusal rate from UK households when it offered free retrofit packages ranging from $£ 6,500$ $£ 25,000$ with reasons of disruption and inconvenience cited as the most common responses 
(Affinity Sutton 2011). Sustainable interventions must hence not only explore alternatives to current norms but also offer options that satisfy needs in a more fulfilling way (Hofstetter, et al 2006, p.110).

This research thus intends to highlight the overlooked triggers of happiness in a domestic context, particularly the social aspects, and their implications for design for happiness in the home. This paper focuses on the first study, discussed in the following sections.

\section{Exploring Design for Happiness in the Home}

The aim of this study was to identify important practices and corresponding needs for home life happiness and, on that account, locate potential design opportunities. The contemporary western home is a private space (Hareven 1991; Crabtree and Rodden 2004). Consequently, methods that would allow the collection of data in a semi-open, non-intrusive manner were chosen to understand the emic experiences of participants (Aldiabat and Le Navenec 2011).

The particular focus of this was on the emotional aspects of home life. Notably, image making (for example, mood drawings) has been shown to activate the emotional centres of the brain relevant to that particular mood (Lusebrink and Alto 2004). Additionally, it has been suggested that we stuggle to engage in rational and emotional thinking simultaneously (Jack, et al 2012). Accordingly, a creative method using participant-generated imagery was chosen for this study.

\subsection{Method - Eliciting Emotions through Photo Elicitation}

For this study, photo elicitation was used as both an interview and creative method to stimulate emotional contemplation over logical. Photo elicitation is a qualitative method that uses images either supplied by the researcher or generated by the participants to evoke more emotional and truthful responses during interview sessions (Harper 2002; Rose 2007). These images can serve as reference points for the initiation of conversation and aid in memory recollections (ibid). Participant-generated photography can be particularly useful when trying to encourage reflection on previously unconsidered topics (Rose 2007; Lo 2011b). In this case, it allowed participants to follow clear guidelines and capture specific visual aspects of home life with freedom and control, while engaging them on an emotional level.

\subsection{Sampling Strategy}

This qualitative study used criterion sampling (Creswell, 2013, p.119) to obtain 13 volunteers from 10 U.K. home-owning families of similar socio-economic backgrounds. See table 1 for participant break down. 
Table 1 1st study sample breakdown (shaded boxes indicate those who took part in each household, $F / M$ represents gender and the number stands for age)

\begin{tabular}{llllllll}
\hline $\begin{array}{l}\text { Household } \\
\text { (H\#) }\end{array}$ & $\begin{array}{l}\text { Adult 1 } \\
\text { (A1) }\end{array}$ & $\begin{array}{l}\text { Adult 2 } \\
\text { (A2) }\end{array}$ & $\begin{array}{l}\text { Adult 3 } \\
\text { (A3) }\end{array}$ & $\begin{array}{l}\text { Adult 4 } \\
\text { (A4) }\end{array}$ & $\begin{array}{l}\text { Child } \\
1 \\
\text { (C1) }\end{array}$ & $\begin{array}{l}\text { Child 2 } \\
\text { (C2) }\end{array}$ & $\begin{array}{l}\text { Child 3 } \\
\text { (C3) }\end{array}$ \\
\hline 1 & F, 41 & M, 40 & M, 6 & F, 3 & \\
\hline 2 & F, 25 & M, 52 & F, 49 & F, 80 & M, 12 & M, 11 & \\
\hline 3 & F, 45 & M, 45 & & M, 10 & F, 7 & \\
\hline 4 & M, 43 & F, 37 & & F, 1 & & \\
\hline 5 & F, 34 & M, 34 & & F, 1 & M, 4 & \\
\hline 6 & F, 34 & M, 34 & M, 4 & & \\
\hline 7 & F, 34 & M, 36 & & F, 2 & & \\
\hline 8 & M, 43 & F, 42 & & M, 14 & M, 10 & \\
\hline 9 & M, 53 & F, 48 & F, 14 & F, 12 & M, 12 \\
\hline 10 & M, 52 & F, 49 & F, 17 & M, 15 & \\
\hline
\end{tabular}

This target group was chosen for several reasons. Homeowners tend to have more freedom in altering this environment when compared with non-homeowners. Therefore, their homes would offer a more honest reflection of their preferred lifestyles. Also, families, when compared to non-family households, arguably find it more challenging to maintain happy and sustainable lifestyles due to their hectic daily routines and responsibilities and would be more beneficial to the study.

\subsection{Procedure}

The participants were asked to create a photographic narrative of two representative days at home - one working and one non-working day (see figure 3 for examples). 


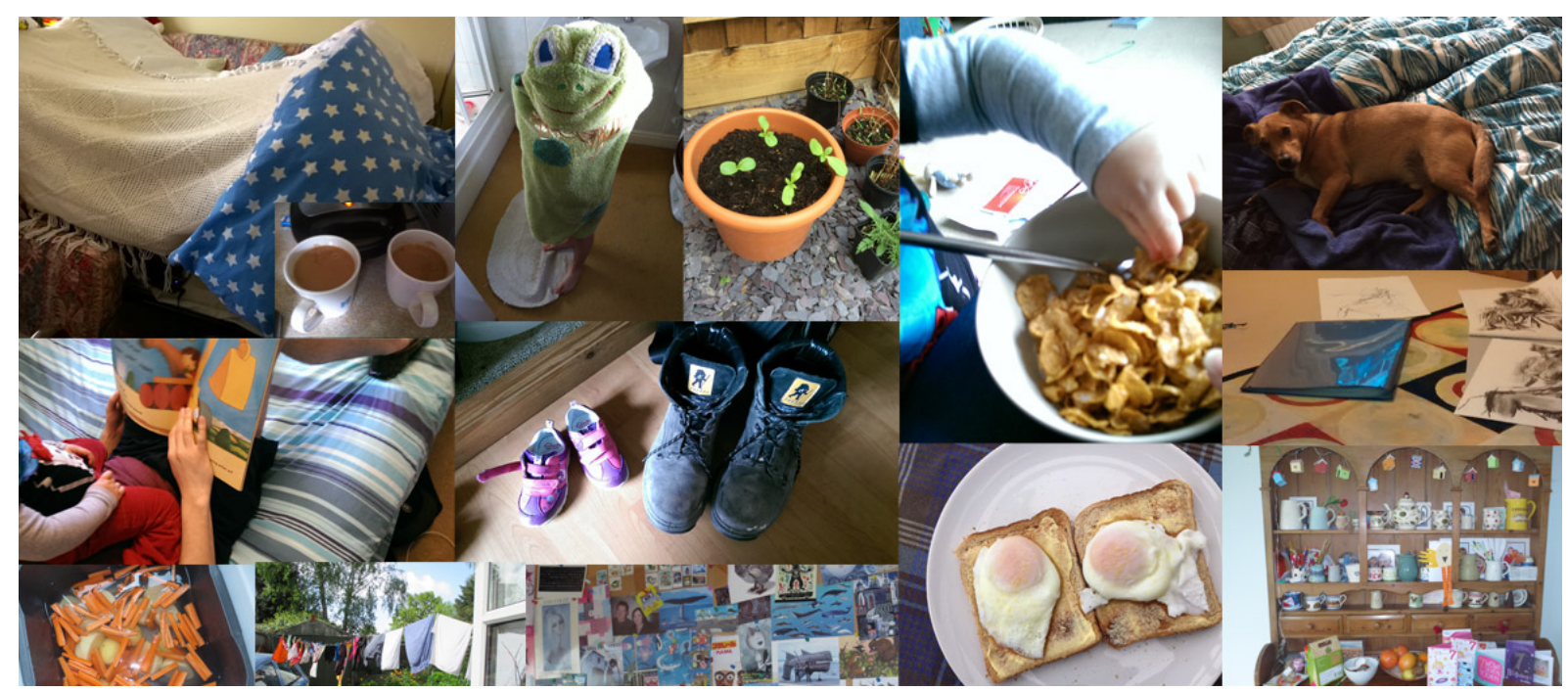

Figure 3 Sample of images captured by participants during the study.

To prevent any a priori and/or external influence on participants, the specific goals of the study were not broadcasted to them prior to the task. Participants had the freedom to take as many or as few photographs as they wanted. Once the images were completed, they were sent by email for analysis, conducted through analytical memos. The results were then triangulated against those of follow-up semi-structured interviews. These interviews facilitated the live expression of feelings and the use of semi-structured questions, which could be adjusted in response to interesting replies or body language (Robson 2011). The questions were generated from the findings of a literature review on concepts of home (i.e. home is a reflection/extension of the self) (Cristoforetti, et al 2011; De Botton 2006) to evoke responses about happiness domestic practices (see table 2).

Table 2 Sample Questions from Interview Schedule.

1. What makes home feel like home for you?

2. How does your home reflect/not reflect you?

3. What do you need in a home?

The semi-structured interviews were kept under an hour and were mostly participant-led. All interviews were audio-recorded and body language was also noted. Session summary sheets were used to summarise main findings (i.e. suggested happiness enhancing home practices) for each interview (Robson, 2011, p.473).

\subsection{Analysis Strategy}

The collective results from the photo-elicitation activities and following semi-structured interviews were analysed inductively using a thematic analysis (Corbin and Strauss, 2008) to locate happiness triggers in the home. This was done using open coding (ibid) by employing sensitising questions such as "What are people doing?" and "How does this enable 
happiness?" Theoretical questions and the flip-flop technique were used to axial code the data (ibid; Robson 2011). The constant comparative method was incorporated throughout to compare the arising concepts, locate commonalities and continuously rework the data into a sound initial theory (Corbin and Strauss 2008).

Furthermore, as previous work has shown a correlation between happiness and sustainability cues (Escobar-Tello 2010) this analysis strategy attempted to situate this within the domestic space to establish how people's happiness at home might correlate to sustainability. A deductive analysis was carried out on resulting themes and properties using Escobar-Tello's (2010) a priori codes (see figure 4) for happy sustainable societies.

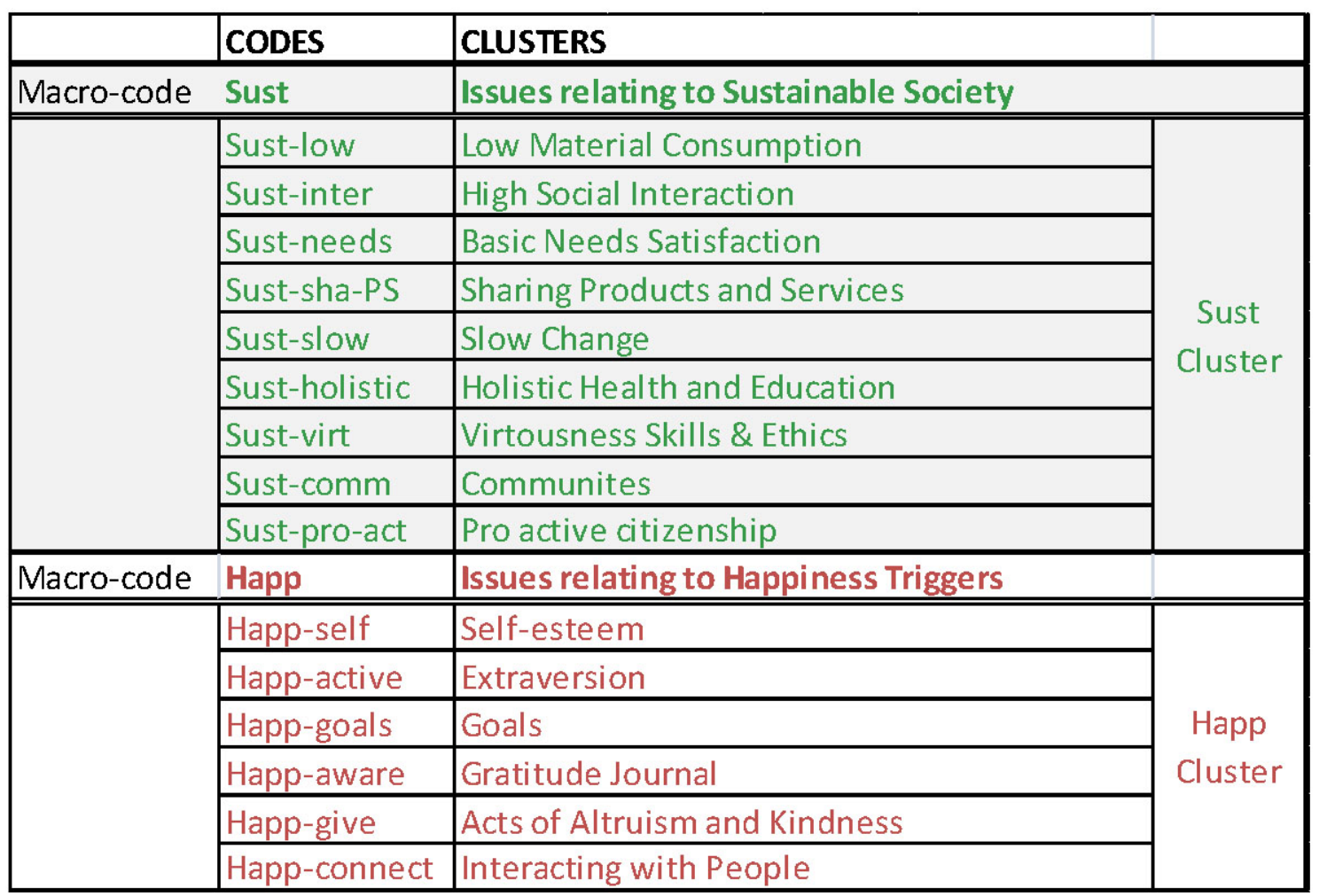

Figure 4 Example of the a priori codes for happy sustainable societies (Escobar-Tello 2010) used in the second phase of analysis to deductively analyse findings for the location of happy and sustainable practices in the home.

This allowed initial connections to be hypothesised between domestic happiness behaviours and sustainable lifestyles, and identify which areas held the most potential for later design for happiness interventions. The counting technique (Miles and Huberman, 1994, p.215) was then employed to establish which categories and properties appeared more or less often (see figure 5). 


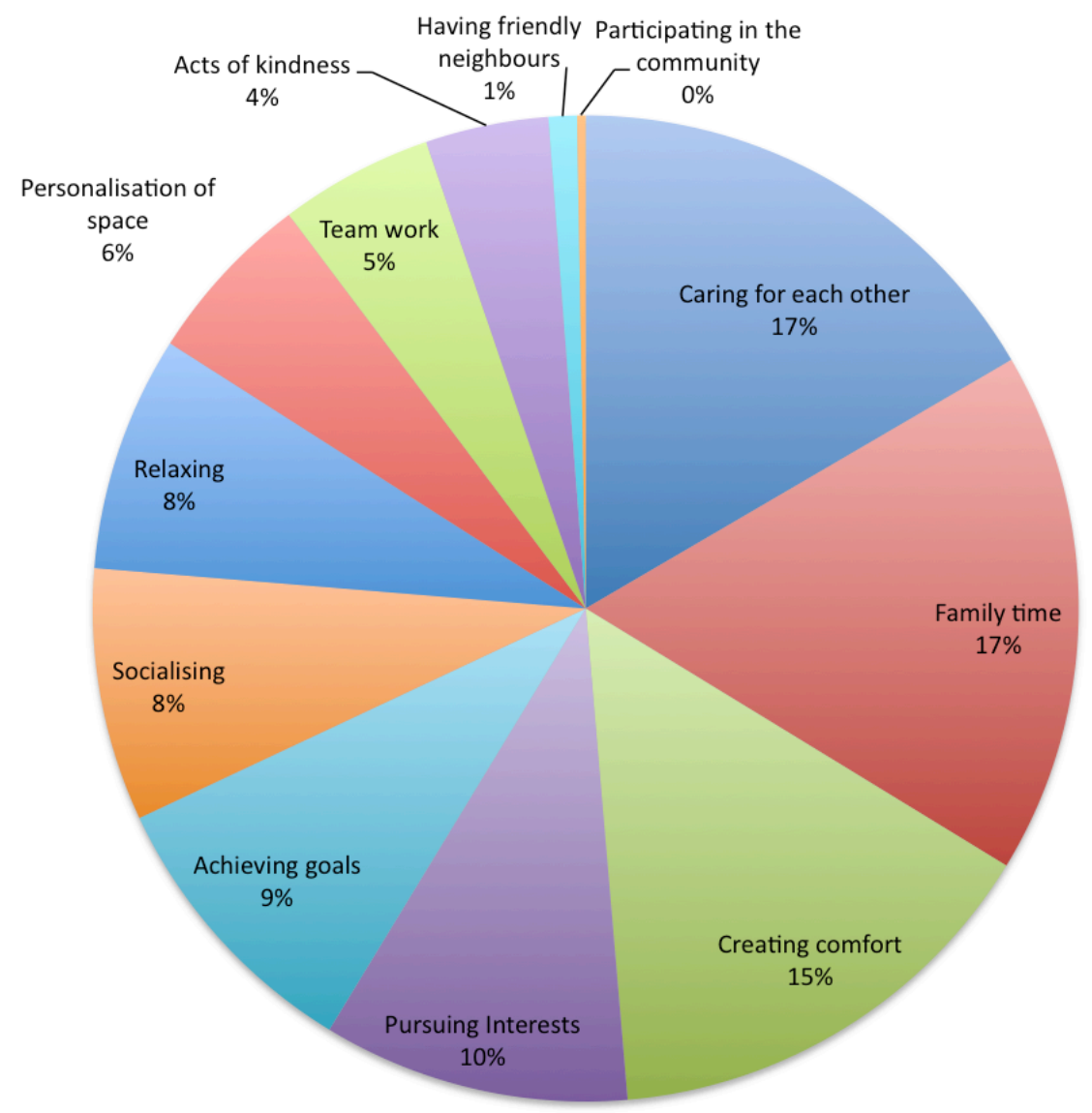

Figure 5 Pie chart detailing the frequency each code for home happiness activities occurred in the data.

\section{Findings and Discussion}

The results revealed possible areas for design for happiness in the home. These findings and their implications for future design for happiness in the home will be discussed in the following sections.

\subsection{Effective Use of Photo Elicitation as a Creative Method}

The creative element of photo elicitation (i.e. participants told their domestic stories through self generated imagery) engaged participants successfully in the activity. Participants appeared to emotionally connect to their domestic routines. Furthermore, by deciding and editing what photos to include or remove, they reflected on how they wanted home to be represented. Consequently, this led them to consider what this inferred about their needs, experiences and happiness in the home (see figure 6). 


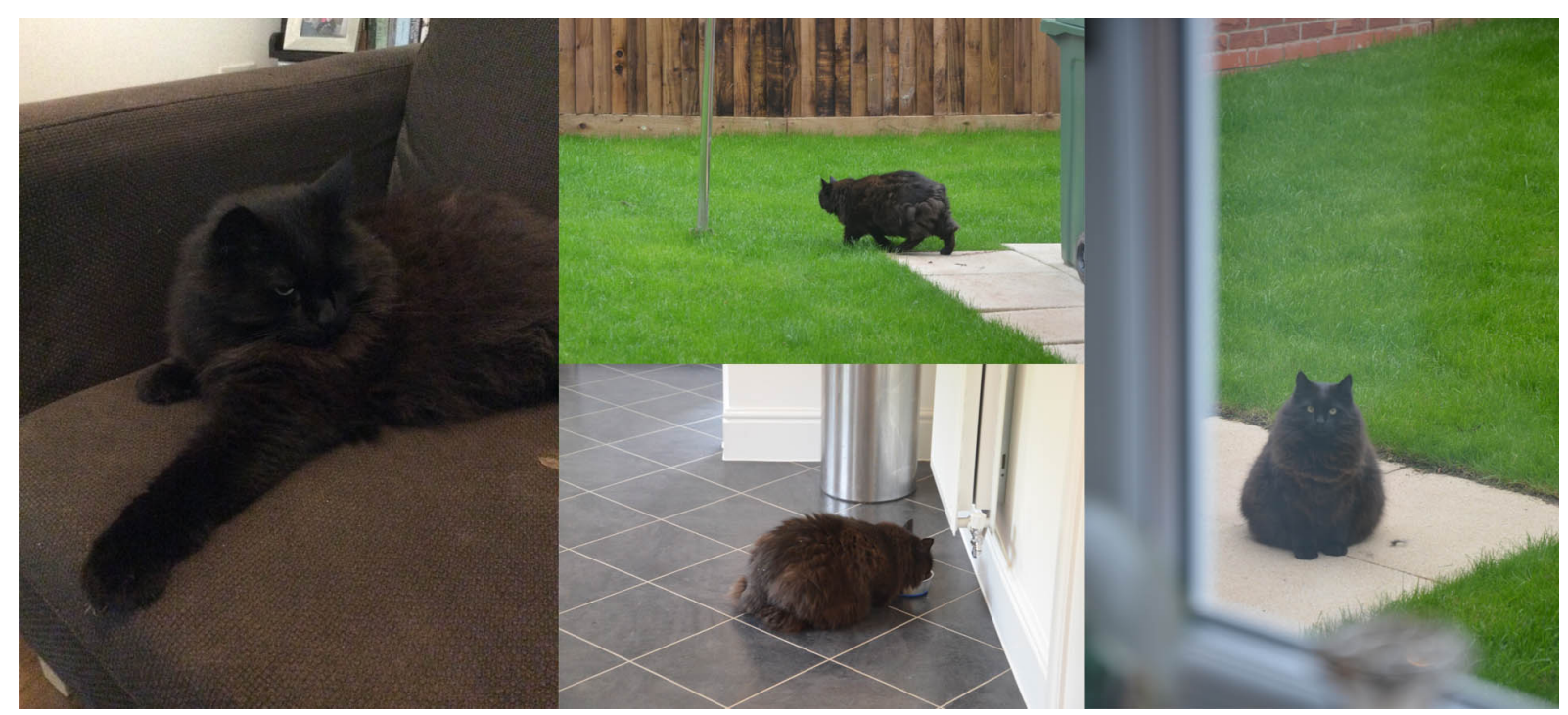

Figure 6 Examples of images captured by one participant who remarked, "I don't know why l ended up taking loads of pictures of the cat... I don't know what that says". Later when asked what she needed in a home she responded; "I think you need a cat in the house... I think for me if you have a pet they become part of your life... it's a companionship thing really."

This sensitisation also allowed for more emotionally rich and honest discussions at the interview stage, which included both negative and positive aspects of home life. This was identified from (1) participant's open commentary of situations or areas e.g. "... with the kids it would be chaos if we tried to sit in there" or (2) their reflections e.g. "...we're working towards me getting my life back so I'm doing quite a lot of drawing and painting" and (3) what featured most frequently in the images.

\subsection{Triggers of Negative and Positive Emotions in the Home}

Negative responses consistently occurred around imagery depicting household chores or when values of household members clashed i.e. different views on how things should be done in the space (see figure 7). 


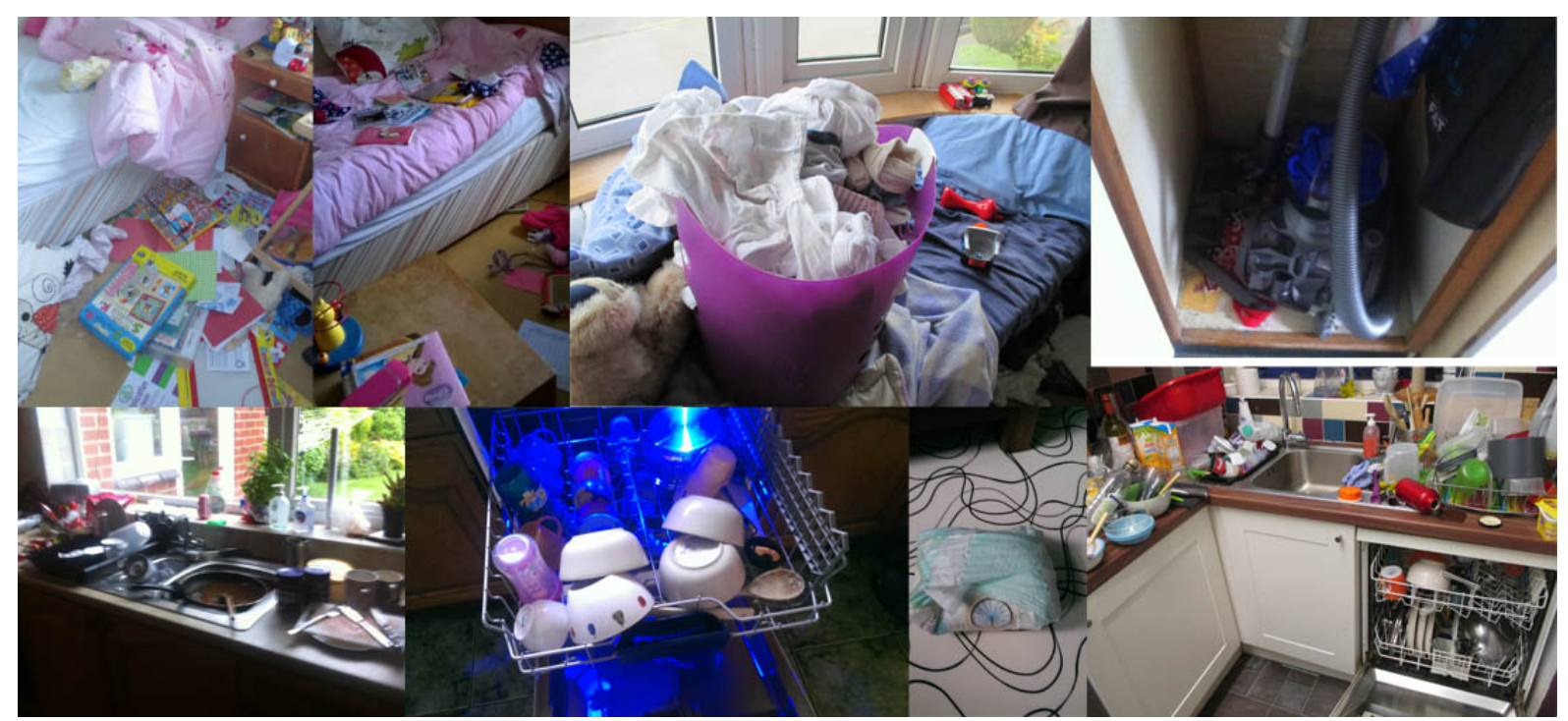

Figure 7 A selection of images captured by participants around negative topics such as household chores and conflicting ideals i.e. of how a space should be maintained.

However, participants were often quick to reflect that this conflict resulted from different perspectives and were not created in malice. For example, one participant remarked, "I have to wrestle with my need to try and order things versus everybody else's need to try and live their life". This negative feedback was quickly deflated through a shown understanding and willingness to compromise.

Household chores on the other hand were often described as work that detracted from leisure time. One participant commented that his ideal home would be one without maintenance after reflecting on the amount of time a recent DIY job had detracted from time with his children. Another participant remarked that she didn't think that household chores should be part of her time/leisure time off, commenting, "I don't like how it intrudes on your home". This discussion of negative themes allowed for a deeper assessment of what led to positive experiences in the home i.e. the importance of family time and awareness of personal differences.

Having said this, the majority of the imagery generated was of a positive nature and often depicted elements such as family members, pets, relaxation periods and hobbies (see figure 8). 


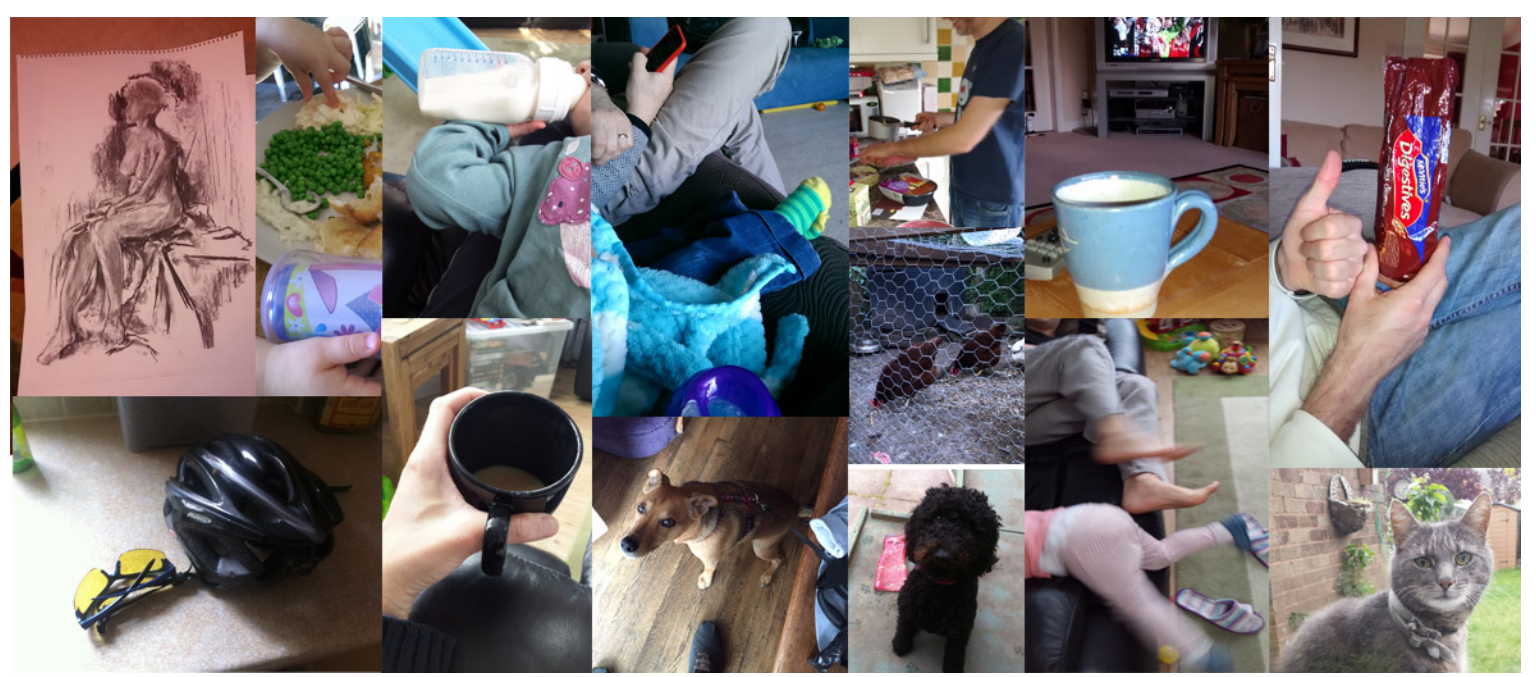

Figure 8 A selection of images captured by participants around positive themes such as spending time with family, pets, relaxing and pursuing interests.

Discussions with participants around these topics revealed that positive periods were often supported and/or strengthened by others in the household through acts of cooperation, kindness or their presence. For instance, there was clear evidence of teamwork in all households interviewed where one parent performed one activity such as making the dinner while the other would put the children to bed. This would then be often preceded by a period of relaxation in each other's company, sometimes in front of the television, other times engaged in different docile activities such as reading. For example one participant recalled a particularly pleasant day where after a "full-on evening" her husband rang for a take away while she read a story to their child and then later together they "... just had to wait for it to arrive" while they had a glass of wine and "...just watched Tele". These cooperative relationships evidently encouraged healthy routines of work, play and rest, contributing to overall happiness in the home.

\subsection{Relational Messages in the Home}

The imagery greatly aided the discussions of the sometimes-sensitive negative and positive subjects of domestic life. It enabled a relaxed atmosphere for conversation by taking the initial attention off the participant and providing a common ground between the interviewer and interviewee. These discussions also brought to light relational messages in the home and how previous pleasant experiences with family could encourage positive over negative.

For example, one participant talked about how his partner's jewellery tree was a positive encapsulation of the whole family. On this jewellery tree were gifts that he had previously bought his wife to say thanks for a number of different reasons. Additionally, the children chose the jewellery tree while the family were on holiday. Accordingly, it elicited positive relational messages by triggering memories of happy family experiences (see figure 9). 


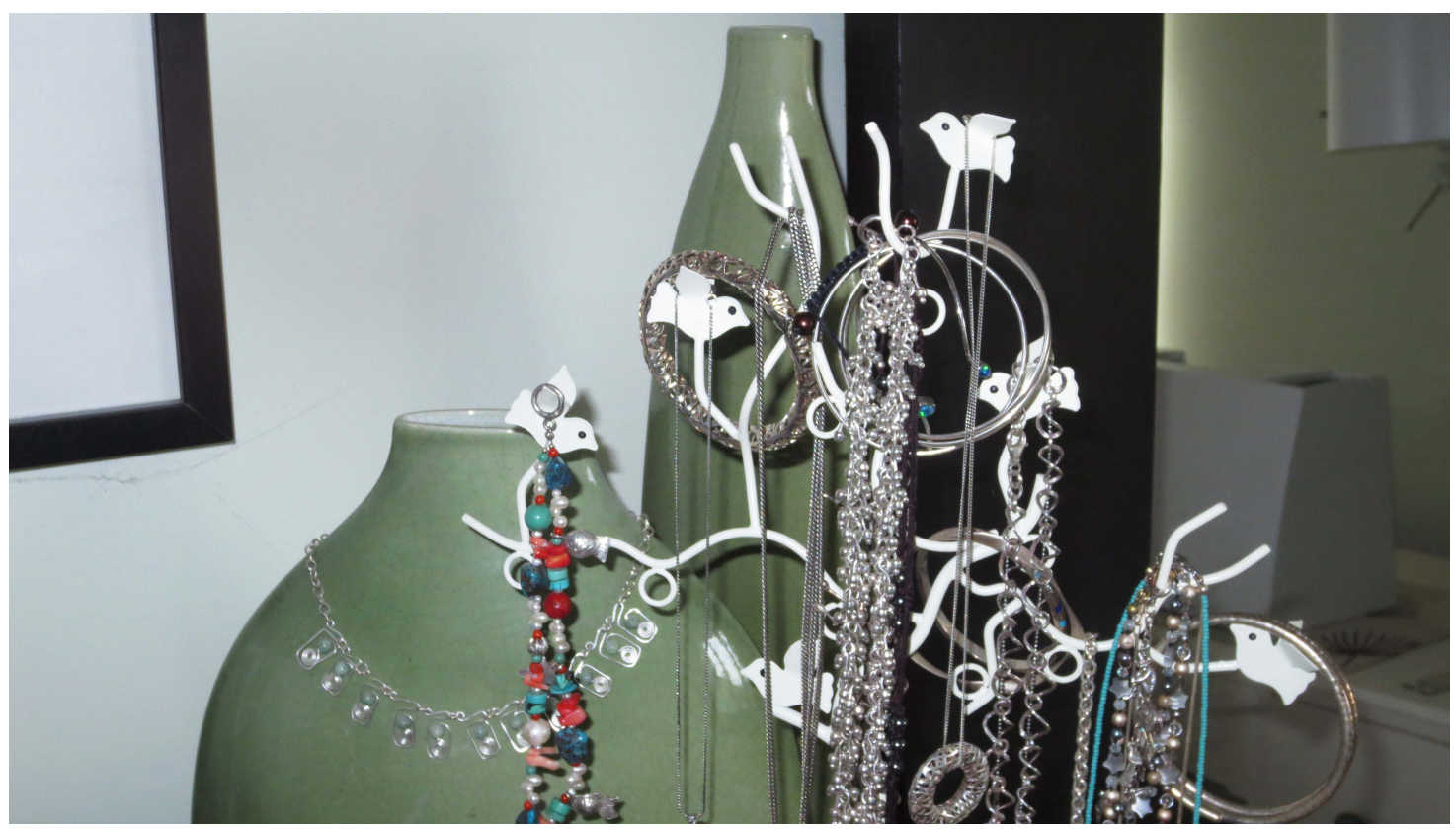

Figure 9 An image of a jewellery tree belonging to a participant's partner that triggered positive relational messages for him i.e. the jewellery tree contained gifts that he had bought his partner as thank-you presents for previous acts of kindness she had done for him.

Furthermore, another participant stated that home feels like home because "It has lots of stuff that the kids have made and I've made, stuff that means something to us". Artefacts in the home could hence be seen to play an additional role outside of function and domestic adornment by providing reminders of previous pleasant family experiences, encouraging positive relational messages and a happy home environment.

\subsection{Happiness-Needs and Motivations in the Home}

Through the collective analysis of the resulting negative and positive themes from the verbal and visual data, it was possible to identify activities associated with happiness in the home. These were initially divided into care for the self, family, community and home. Links to the characteristics of happy sustainable societies could then to be drawn using Escobar-Tello's (2010) a priori codes (see table 1). 


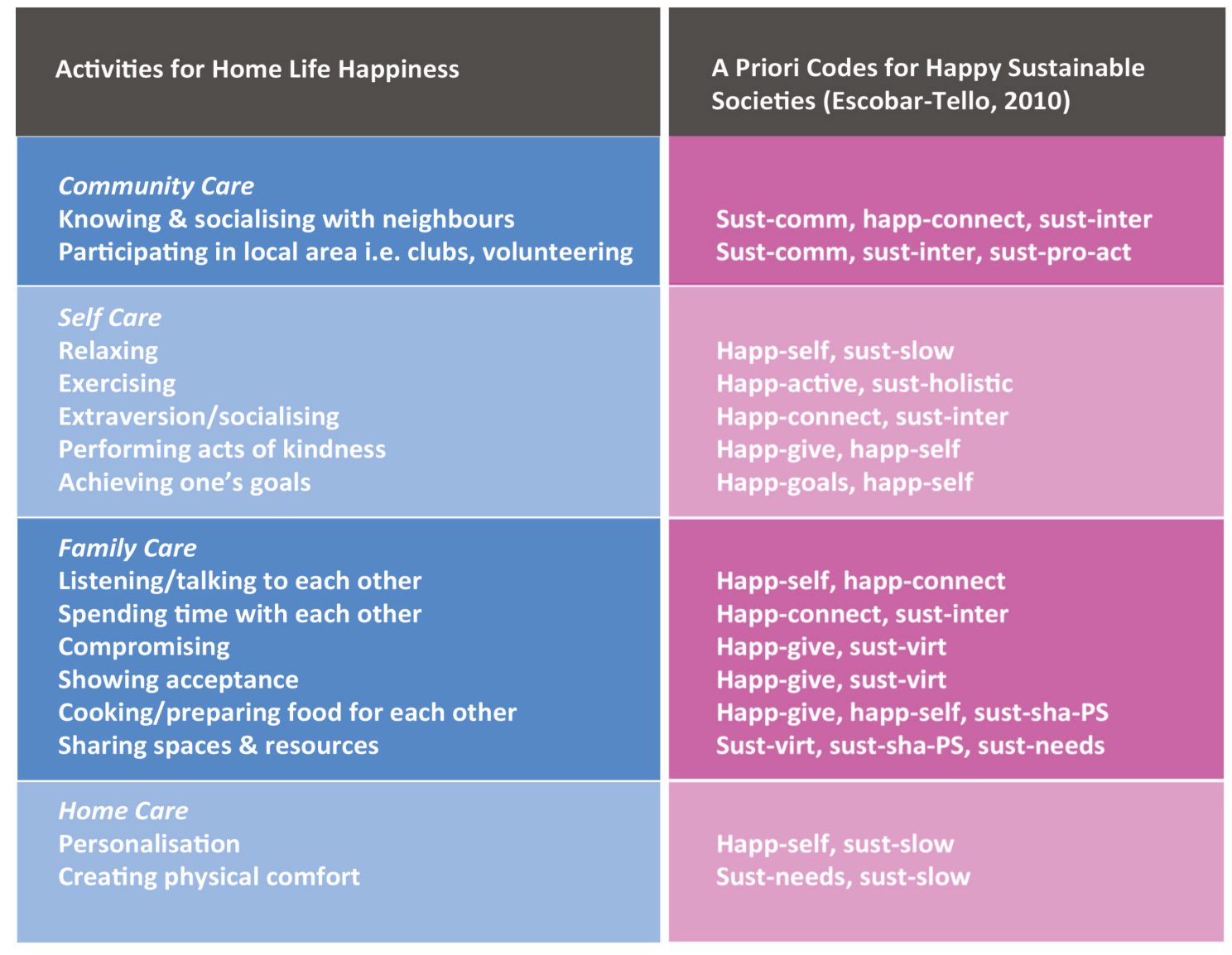

Table 1 A sample of activities related to happiness in the home (blue section of table) that emerged during initial data analysis and links to happy sustainable society characteristics using Escobar-Tello's (2010) a priori codes (pink section of table) (Original work by CorriganDoyle, Escobar-Tello and Lo ).

Consequently, further analysis of these activities revealed underlying needs for happiness in the home (see table 2). 

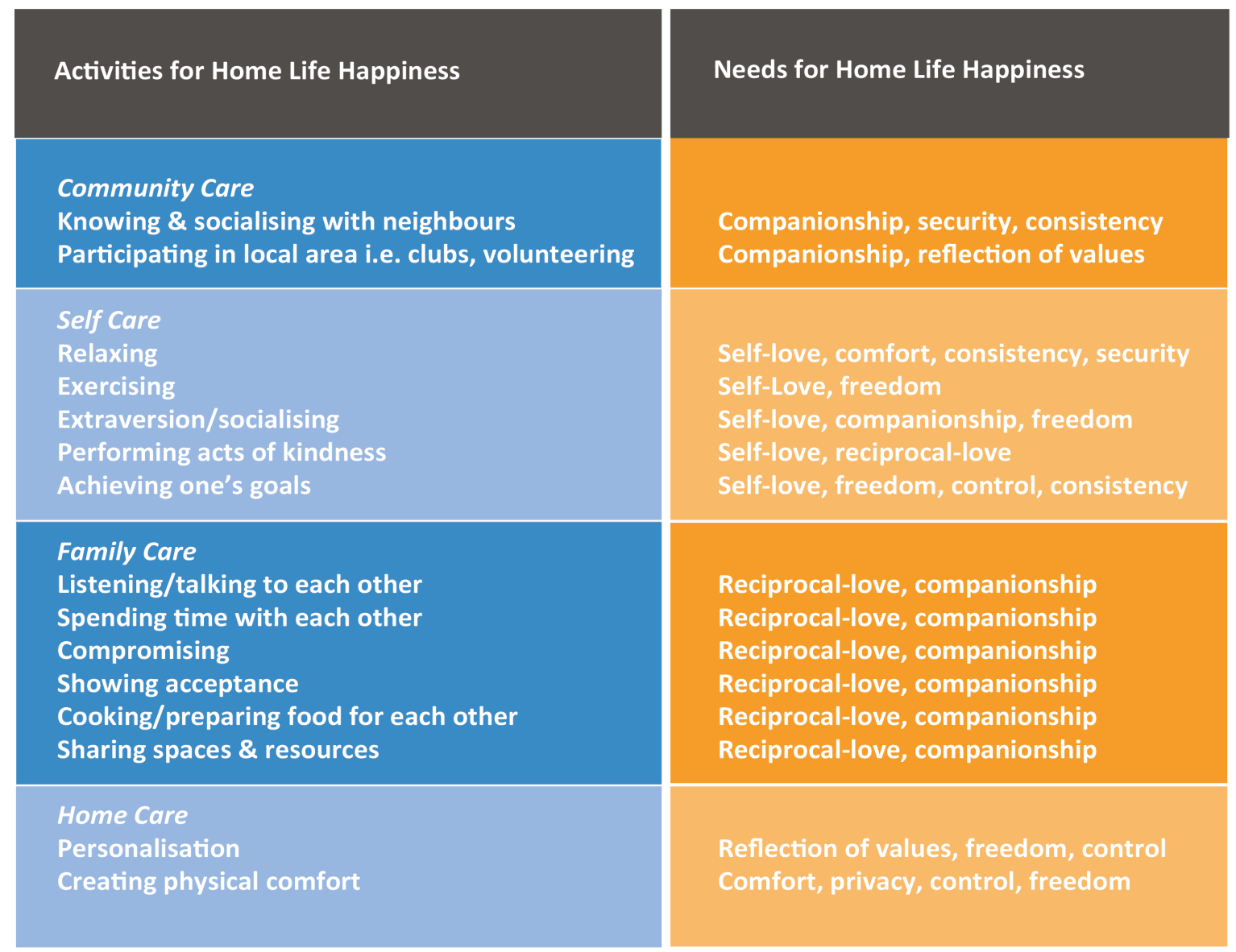

Table 2 A sample of activities related to happiness in the home (blue section of table) and hypothesised implied needs for each (yellow section of table) (Original work by CorriganDoyle, Escobar-Tello and Lo).

For example, relaxing (under self-care) appeared to indicate the need for self-love, and also comfort, security and consistency as these needs afforded relaxation. Similarly, spending time with family (under family care) seemed to expose the need for reciprocal love and companionship. From this, home happiness activities (i.e. pursuing interests) were grouped with corresponding needs (i.e. self-love) (see table 3). 


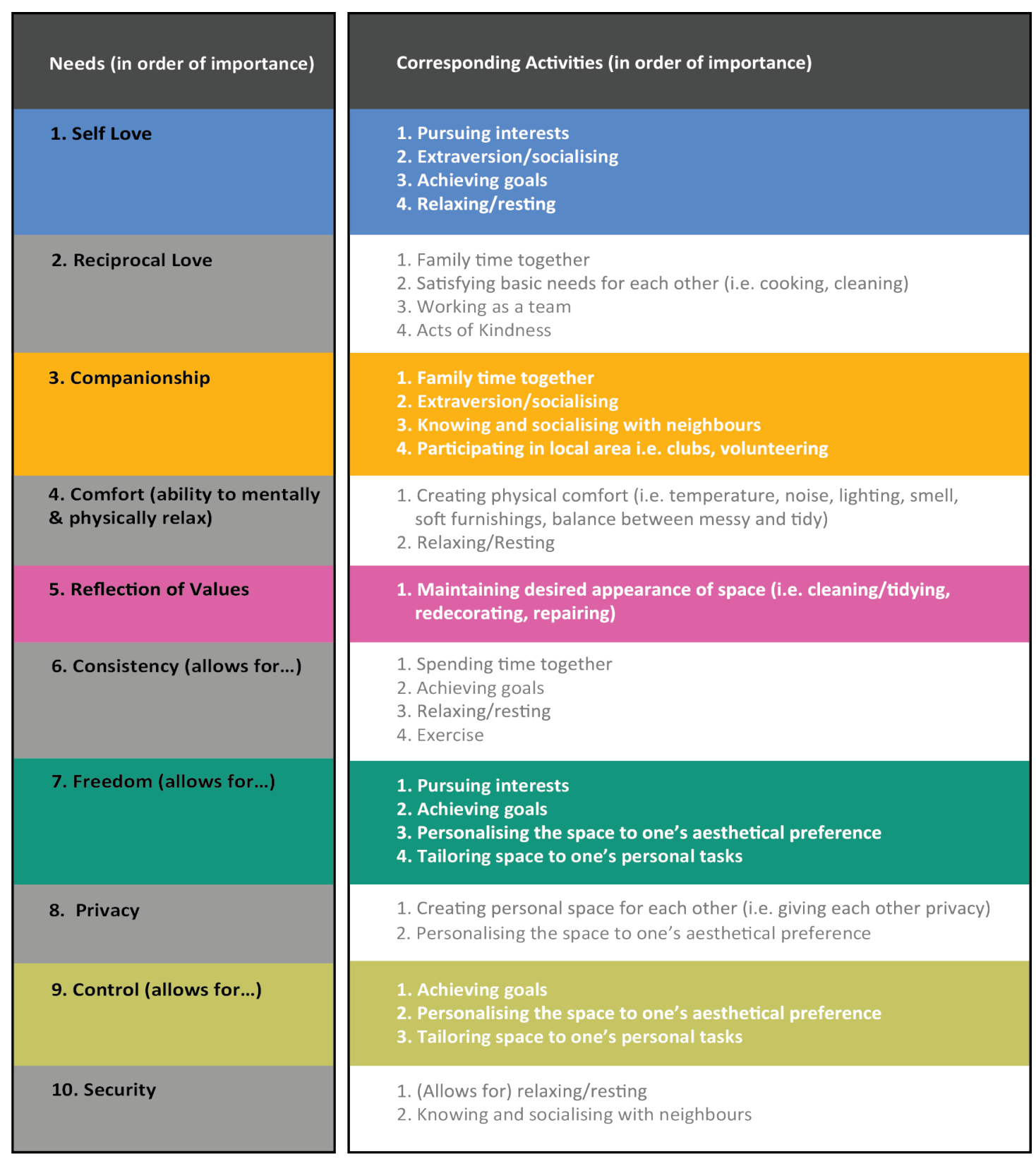

Table 3 An example of the ten needs, in order of occurrence, that emerged from the data and their corresponding activities - located in the same colour adjacent sections of the table, also in order of frequency (Original work by Corrigan-Doyle, Escobar-Tello and Lo).

The importance of each need could then be determined by counting the number of instances its related actions occurred. This led to a tentative ranking system of ten psychological needs for home life happiness (see table 3 ). The results indicated that the need for love, firstly self-love and secondly reciprocal love, overwhelmingly dominated the motivation for home happiness activities. Participants indicated a need for self-love by openly stating the importance of spending time on personal interests (e.g. art making, running) (see figure 10) and socialising (e.g. attending a book club). For example, one 
participant quoted the following; "I'm not spending my time thinking of the family all the time. I am thinking of myself as well and doing my own thing. I think that is important".

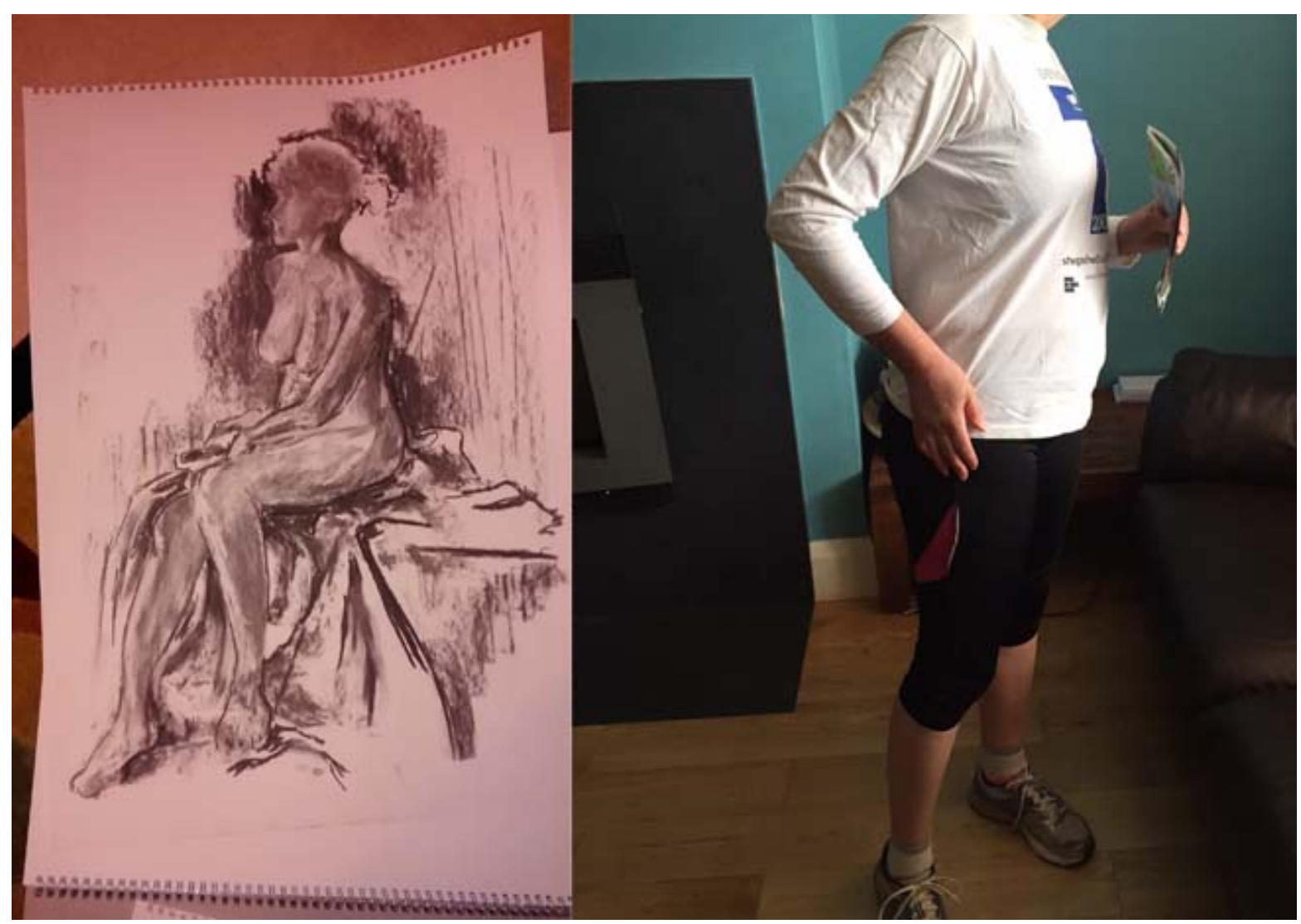

Figure 10 Two sample images portraying activities of self-love such as art making and exercising.

The need for reciprocal love was made evident from the extended periods participants reported spending with family and satisfying basic needs for each other such as cooking. The need for companionship was also often stressed. Many participants remarked that home did not feel like home when their partner or children were away. It was described as 'really empty' and missing familiar sounds. Accordingly, this made the need for consistency evident. When asked what made home feel like home, many responded with 'having the family around' and 'laughter'. Another participant described the predictable domestic routines of his cat as 'comforting'.

Comfort (i.e. creating a relaxing atmosphere) also played a role in maintaining a happy home, which was often described as 'warmth' in the home. Many agreed that home should be a "space to relax" but also a space with control and freedom to create a context suitable to personal preferences and needs. Evidently control and freedom also emerged as reoccurring needs. For example, one participant commented "functionality is important and the ability to get on and do things". Furthermore, the personalisation of homes to reflect the values of their owners also appeared to play a role in facilitating their experienced happiness. One participant remarked he was proud of the alterations he made to his home 
because in his view he had given it greater "purpose and meaning". Many participants also emphasised a need to maintain a separation between their work life and home life and in some instances from others in the household at particular times i.e. early mornings. Privacy was therefore identified as another need that corresponded to these responses. Finally, security was conceptualised as the final need to emerge from the data. For example, some participants talked about alterations or decisions they had made about their home to create a safer environment for their children. One participant remarked "It doesn't feel like home if my son can't get up the stairs".

The conceptualisation of these happiness-needs in relation to positive activities in the home allowed connections to be drawn between those for happy sustainable societies (see table 4). 


\begin{tabular}{|c|c|}
\hline Corresponding Activities (in order of importance) & $\begin{array}{l}\text { Corresponding Characteristics for Happy Sustainable } \\
\text { Societies (Escobar-Tello, 2010) }\end{array}$ \\
\hline $\begin{array}{l}\text { 1. Pursuing interests } \\
\text { 2. Extraversion/socialising } \\
\text { 3. Achieving goals } \\
\text { 4. Relaxing/resting }\end{array}$ & $\begin{array}{l}\text { Achieving/pursuing goals, self esteem } \\
\text { Extraversion, high interaction } \\
\text { Achieving/pursuing goals, self esteem } \\
\text { Slow change, holistic health, self esteem }\end{array}$ \\
\hline $\begin{array}{l}\text { 1. Family time together } \\
\text { 2. Satisfying basic needs for each other } \\
\text { 3. Working as a team } \\
\text { 4. Acts of Kindness }\end{array}$ & $\begin{array}{l}\text { Extraversion, high interaction, low material consumption } \\
\text { Satisfying basic needs } \\
\text { Extraversion, high interaction } \\
\text { Acts of kindness, self esteem }\end{array}$ \\
\hline $\begin{array}{l}\text { 1. Family time together } \\
\text { 2. Extraversion/socialising } \\
\text { 3. Knowing and socialising with neighbours } \\
\text { 4. Participating in the local community }\end{array}$ & $\begin{array}{l}\text { Extraversion, high interaction, low material consumption } \\
\text { Extraversion, high interaction } \\
\text { Extraversion, high interaction, strong communities } \\
\text { Extraversion, high interaction, strong communities, } \\
\text { active citizenship }\end{array}$ \\
\hline $\begin{array}{l}\text { 1. Creating physical comfort } \\
\text { 2. Relaxing/Resting }\end{array}$ & $\begin{array}{l}\text { Holistic health, satisfying basic needs, self esteem } \\
\text { Holistic health, self esteem }\end{array}$ \\
\hline $\begin{array}{l}\text { 1. Maintaining desired appearance of space } \\
\text { 2. Personalising the space to one's aesthetical preference }\end{array}$ & $\begin{array}{l}\text { Slow change, self esteem, achieving/pursuing goals } \\
\text { Holistic health, self esteem }\end{array}$ \\
\hline $\begin{array}{l}\text { 1. Spending time together } \\
\text { 2. Achieving goals } \\
\text { 3. Relaxing/resting } \\
\text { 4. Exercise }\end{array}$ & $\begin{array}{l}\text { Extraversion, high interaction } \\
\text { Achieving/pursuing goals, self esteem } \\
\text { Holistic health, self esteem } \\
\text { Holistic health, self esteem }\end{array}$ \\
\hline $\begin{array}{l}\text { 1. Pursuing interests } \\
\text { 2. Achieving goals } \\
\text { 3. Personalising the space to one's aesthetical preference } \\
\text { 4. Tailoring space to one's personal tasks }\end{array}$ & $\begin{array}{l}\text { Achieving/pursuing goals, self esteem } \\
\text { Achieving/pursuing goals, self esteem } \\
\text { Holistic health, self esteem } \\
\text { Holistic health, self esteem }\end{array}$ \\
\hline 1. Creating personal space for each other & Acts of kindness \\
\hline $\begin{array}{l}\text { 1. Achieving goals } \\
\text { 2. Personalising the space to one's aesthetical preference } \\
\text { 3. Tailoring space to one's personal tasks }\end{array}$ & $\begin{array}{l}\text { Achieving/pursuing goals, self esteem } \\
\text { Holistic health, self esteem } \\
\text { Holistic health, self esteem }\end{array}$ \\
\hline $\begin{array}{l}\text { 1. (Allows for) relaxing/resting } \\
\text { 2. Knowing and socialising with neighbours }\end{array}$ & $\begin{array}{l}\text { Holistic health, self esteem } \\
\text { Extraversion, high interaction, strong communities, } \\
\text { active citizenship }\end{array}$ \\
\hline
\end{tabular}

Table 4 This table, when read horizontally, shows connections made between activities for happiness in the home and those for happy sustainable societies relevant to this study (Original work by Corrigan-Doyle, Escobar-Tello and Lo).

For instance, satisfying the need for companionship by knowing and socialising with one's neighbours could be seen to potentially create stronger communities, and by fulfilling the need for self-love through pursing one's interests, the maintenance of self-esteem and achievement of goals may also occur.

Overall, the activity of being and socialising with family seemed to be the one that crossed over into many needs (i.e. self-love, reciprocal love, companionship) while also closely linking with characteristics of happy sustainable societies such as extraversion and sharing of products and resources. For example, self-love activities such as pursing interests, achieving 
goals and relaxing could be conducted with other family members, thus creating a context where needs for reciprocal love and companionship may also be met. Furthermore, previous positive experiences with family seemed to facilitate positive relational messages, aiding in times of stress, encouraging understanding and cooperation. Extending and supporting positive family interactions therefore appeared to exhibit the most promise for design for happiness in the home - for example, a design intervention that enables family members to synchronise their rest periods together, involving the use of a bread maker to bake fresh bread on their return.

\section{Conclusions}

This study aimed to locate the characteristics of happy sustainable societies in a home context and thus identified potential areas for design for happiness in the home as a complex system. The use of photo elicitation in this creative manner helped participants to reflect and become better aware of the emotional significance of their daily activities and qualities in their home experiences. Furthermore, this allowed them to respond more honestly and openly during interview sessions. The resulting rich verbal and visual data detailing daily activities and opinions allowed for the conceptualisation of ten explanatory motivating needs for common domestic activities (see table 3).

The need for love, divided into self-love and reciprocal love, overwhelmingly dominated all other motivations for activities in the home. It also appeared to be strongly assisted by supportive relationships with family members. Given the context of this study, it could be suggested that this need is particularly prevalent in family homes and its satisfaction a particularly strong indicator of happiness in this context. For example, in a work environment scenario, the strength of each identified need may shift around or be conceptualised differently.

When considering positive family time, the need for love and companionship appeared to share a more predominant symbiotic relationship than all other identified needs. For example, the practices of self-love could be seen to overlap with those associated with reciprocal love and companionship and vice versa i.e. a participant could conduct an activity of interest with or while relaxing with his/her partner and children. The fulfilment of the need for self-love in this family context could thus simultaneously satisfy the need for reciprocal love and companionship at the same time. Positive family experiences together were therefore concluded to be necessary components of happy homes in these instances.

The associated activities around family time also appeared to strongly resemble the overlapping characteristics of happy sustainable societies such as extraversion, sharing of products and resources, and low consumption (see table 4). For example, if one spends more time with one's family in the same space, as suggested by the findings, family bonds are strengthened and hypothetically fewer resources are consumed or wasted. Expectedly, this behaviour encourages cooperation and better communication between family members through experiences that involve preparing and eating meals together or simply enjoying 
each other's company. Hence, happy sustainable home experiences could be emphasised by encouraging positive family time together.

In light of this, it appeared that expanding shared time with family showed the most promise for design for happiness in the home. Further consideration of the data led to the hypothesis that this could be achieved by design concepts, which, for example, extended family periods of rest and group activities together as these already occurred naturally in household dynamics. Furthermore, after discerning some relational qualities of home life from the data, it appeared that previous pleasant family experiences - symbolised through artefacts on display - also played a role in encouraging positive relational messages, strengthening a happy home dynamic. As indicated by the findings, household objects (e.g. jewellery tree) could serve as reminders of happy family memories and kindness, creating a more receptive social context for future positive family experiences. With this in mind, we might consider what shape design for happiness in the home could take, how it will be conceptualised, and what impact it will have on the transition towards happier sustainable homes in the future.

\section{Future Work}

The next stages of this research will look to explore the concept of shared positive family time more deeply using creative methods. This will be conducted through workshops with UK households, and later with service designers. Service design is natural systemic and offers a viable approach to explore the home as a complex system. Accordingly, service design approaches will be employed to conceptualise design interventions for happier and more sustainable homes.

\section{References}

Aristotle (2004). Nicomachean Ethics (Penguin Classics). Edited by Hugh Treddenick, London: Penguin.

Aldiabat, K. \& Le Navenec, C. L. (2011). Clarification of the Blurred Boundaries between Grounded Theory and Ethnography: Differences and Similarities. Turkish Online Journal of Qualitative Inquiry, 2(3), 1-13.

Cipolla, C. \& Manzini, E. (2009). Relational Services. Knowledge, Technology \& Policy 22 (1), 45-50.

City of Norwood Payneham \& St Peters (2012). City Plan 2030: Shaping Our Future (2012 Update). Retrieved from http://www.npsp.sa.gov.au/about_council/strategic_planning/cityplan_2030.

Cohen, L., Manion, L. \& Morrison, K. (2011). Research Methods in Education. $7^{\text {th }}$ Edition. Oxon: NewYork: Routledge.

Corbin, J. \& Strauss, A. (2008). Basics of Qualitative Research. 3rd Edition. Thousand Oaks: SAGE.

Crabtree, A. \& Rodden, T. (2004). Domestic Routines and Design for the Home. Computer Supported Cooperative Work (CSCW), 13(2), 191-220.

Creswell, J. W. (2013). Qualitative Inquiry and Research Design: Choosing Among Five Approaches. Los Angeles: SAGE Publications. 
Cristoforetti, A., Gennai, F. \& Rodeschini, G. (2011). Home Sweet Home: The Emotional Construction of Places. Journal of Aging Studies, 25(3), 225-232.

De Botton, A. (2006). The Architecture Of Happiness. London: Penguin Group.

Department for Environment Food \& Rural Affairs (2013). Environment Fact Sheet. Retrieved from http://tinyurl.com/oorjjm2

Design Council (2014). Double Diamond Model. Retrieved from http://tinyurl.com/qyh5rhk

Diener, E. \& Seligman, M.E.P. (2004). Beyond Money, Toward an Economy of Well-Being. American Psychology Society, 5(1), 1-31.

Dovey, K. (1985). Home and Homelessness: Introduction. In I. Altman \& C.M. Werner (eds), Home Environments (pp. 33-64). New York: Plenum Press.

Escobar-Tello, C. (2010). Explorations on the Relationship between Happiness and Sustainable Design. (Unpublished PhD thesis). Loughborough University.

Escobar-Tello, M.C. \& Bhamra, T. (2013). Happiness as a Harmonising Path for Bringing Higher Education towards Sustainability. Environment, Development and Sustainability, 15(1), 177-197.

Finnsson, P.T. (2006) Culture: The Fourth Pillar of Sustainability. Retrieved from http://nordicway.org/2014/06/culture-fourth-pillar-sustainability

Hamilton, C. (2010). Consumerism, Self-Creation and Prospects for a New Ecological Consciousness. Journal of Cleaner Production, 18 (6), 571-575.

Hamilton, C. (2003). Downshifting in Britain. A sea-change in the pursuit of happines, 2.

Hareven, T. K. (1991). The Home and the Family in Historical Perspective. Social Research, 58(1), 253284.

Harper, D. (2002). Talking about Pictures: A Case for Photo Elicitation. Visual Studies, 17(March), 1326.

Hassenzahl, M., et al. (2013). Designing Moments of Meaning and Pleasure: Experience Design and Happiness, International Journal of Design, 7(3), 21-31.

Henry, S.G. \& Fetters, M.D. (2012). Research Method for Investigating Physician-Patient Interactions. Annals of Family Medicine, 10(2), 118-126.

Hofstetter, P., Madjar, M. \& Ozawa, T. (2006). Happiness and Sustainable Consumption: Psychological and Physical Rebound Effects at Work in a Tool for Sustainable Design. Int J LCA, 1(1), 105-115.

Horton, B. (2005). Sustainable homes - the financial and environmental benefits. Retrieved from: http://www.environment-agency.gov.uk

Ingold, T. (2011). Being Alive: Essays on Movement, Knowledge and Description. London: New York: Routlege.

IPCC (2014). Summary for Policymakers. In C.B. Field et al. (eds), Climate Change 2014: Impacts, Adaption, and Vulnerability. Part A: Global and Sectoral Aspect Contribution of Working Group II to the Fifth Assessment Report of the Intergovernmental Panel on Climate Change (pp. 1-32). Cambridge: New York: Cambridge University Press.

Jack, A.I., Dawson, A.J., Begany, K.L., Leckie, R.L., Barry, K.P., Ciccia, A.H., et al. (2012). fMRI Reveals Reciprocal Inhibition between Social and Physical Cognitive Domains. Neurolmage, 66C, 385-401.

Kasser, T., Rosenblum, K.L., Sameroff, A.J., Deci, E.L., Niemiec, C.P., Ryan, R.M., et al. (2014). Changes in Materialism, Changes in Psychological Well-Being: Evidence from Three Longitudinal Studies and an Intervention Experiment. Motivation and Emotion, 38 (1), 1-22.

Lazarus, N. (2009). Bedzed: Toolkit Part I: A Guide to Construction Materials for Carbon Neutral Developments. Retrieved from http://www.bioregional.com/bedzed-toolkit-part-i/ 
LEEDR: Low Effort Energy Demand Reduction (2014). LEEDR project. Retrieved from http://leedrproject.co.uk/

Lo, K.P.Y. (2011a). Relational Messages In Product Design. In C. Hooper, J. Martens \& P. Markopoulos (eds), Proceedings of DESIRE'11: International Conference on Creativity and Innovation in Design. Paper presented at Eindhoven University of Technology, Eindhoven, 19-21 October (pp. 329-332). New York: ACM.

Lo, K.P.Y. (2011b). Designing Service Evidence for Positive Relational Messages. International Journal of Design, 5(2), 5-13.

Lusebrink, V.B. \& Alto, P. (2004). Art Therapy and the Brain: An Attempt to Understand the Underlying Processes of Art Expression in Therapy. Art Therapy: Journal of the American Art Therapy Association, 21(3), 125-135.

Massey, D.B. (2005). For Space. London: Los Angeles: Singapore: Washington DC: SAGE Publications.

Manzini, E. (2006). Design, ethics and sustainability. Guidelines for a Transition Phase. University of Art and Design Helsinki (June), 9-15.

Miles, M. B. \& Huberman, A.M. (1994). Qualitative data analysis: An expanded Sourcebook. 2nd Edition. California: SAGE Publications.

Nakamura, J., \& Csikszentmihalyi, M. (2002). The Concept of Flow. In C. R. Snyder \& S. J. Lopez (eds), Handbook of Positive Psychology (pp. 89-105). Oxford: Oxford Univeristy Press.

O’Brien, C. (2008). Sustainable Happiness: How Happiness Studies Can Contribute to a More Sustainable Future. Canadian Psychology/Psychologie canadienne, 49(4), 289-295.

Pink, S. (2013). Saturated and Situated: Expanding the Meaning of Media in the Routines of Everyday Life, Media, Culture and Society, 35(6), 677-691.

Pursuit of Happiness (2015). Positive Psychology and the Science of Happiness. Retrieved from http://www.pursuit-of-happiness.org/science-of-happiness/

Reeve, J. (2009). Understanding Motivation and Emotion. Hoboken, NJ: John Wiley \& Sons.

Robson, C. (2011). Real World Research: A Resource for Social Scientists and PractitionerResearchers. $3^{\text {rd }}$ Edition, Oxford: Blackwell Publishers Itd.

Rose, G. (2007). Visual Methodologies: An introduction to the interpretation of visual materials. London: Thousand Oaks: Cardiff: Sage.

Roseman, I. J., Smith, C. A. (2001). Appraisal Theory. In: K. Scherer, A. Schorr, T. Johnstone (Eds.). Appraisal Processes in Emotion: Theory, Methods, Research. Oxford: Oxford University Press.

Sanders, L. (2001). Collective Creativity. LOOP: AIGA Journal of Interaction Design Education, 6(3), 16.

Sanders, E.B. N. \& William, C.T. (2003). Harnessing People's Creativity: Ideation and Expression Through Visual Communication. In J. Langford \& D. McDonagh-Philp (eds), Focus Groups: Supporting Effective Product Development (pp.137-148). Taylor \& Francis.

Sanders, E. B. N. \& Stappers, P. J. (2012). Convivial Toolbox: Generative Research for the Front End of Design. London: Bis Publisher.

Sangiorgi, D. (2011). Transformative Services and Transformation Design. International Journal of Design, 5 (1), 29-40.

Schachter, S. \& Singer, J. E. (1962). Cognitive, Social, and Physiological Determinants of Emotional State. Psychological Review, 69(5), 379-399.

Segliman, M. (2002). Authentic Happiness. New York: The Free Press.

Seligman, B.M.E.P. \& Royzman, E. (2003). Happiness: The Three Traditional Theories. Retrieved from http://tinyurl.com/q2ore75 
Stickdorn, M. \& Schneider, J. (2011). This Is Service Design Thinking. Basics-Tools-Cases. Amsterdam: BIS Publishers.

The Office for National Statistics (2009). Adult Psychiatric Morbidity in England - 2007, Results of a household survey. Retrieved from http://tinyurl.com/l9blxws

UCLG (2015). Culture 21: Agenda 21 for Culture: Actions. Retrieved from http://tinyurl.com/nhsf8ex

UCLG Committee on Culture (2004). Agenda 21 for Culture. Retrieved from

http://tinyurl.com/on2ouao

UK Green Building Council (2015). UK Green Building Council. Retrived from http://www.ukgbc.org/about-us

World Health Organization (2001). The World Health Report 2001. Retrieved from http://www.who.int/whr/2001/en/whr01_en.pdf?ua=1

About the Authors:

Emily Corrigan Doyle is a $\mathrm{PhD}$ researcher from Loughborough University. Her research looks at how design and creativity can be used to improve sustainability and happiness in the home, in particular, art therapy techniques within service design.

Dr Carolina Escobar-Tello is Lecturer in the Loughborough Design School at Loughborough University and Loughborough University in London campus (UK). Her research interests include happiness and well-being, sustainability, social Innovation, creativity, and systemic thinking. She has worldwide professional design experience in the industrial and governmental arena, and her work has been published in journals and international peer reviewed conference proceedings.

Dr Kathy Pui Ying Lo is Academic Lead of Service Design Mini Centre for Doctoral Training and Lecturer in Visual Communication at Loughborough University. She's an international scholar and educator in service design, experience design, emotional design, and visual communication. 